\title{
The German ochratoxin A project: Contamination of foods and consumer exposure
}

\author{
Manfred GAREIS*1, Joachim WOLFF ${ }^{* 2}$, Horst BRESCH ${ }^{* 3}$, Günther ENGEL*4, \\ Heino ROSNER*5, Paul MAJERUS*6, Rainer SCHEUER*1 \\ and Constanze Cholmakow-BODECHTEL*7
}

\author{
${ }^{*}$ Institute for Microbiology and Toxicology, Federal Center of Meat Research (BAFF) \\ (D-95326 Kulmbach, Germany) \\ *2Institute for Biochemistry of Cereals and Potatoes, Federal Centre for Cereal, Potato and Fat Research (BAGKF) \\ (D-32756 Detmold, Germany) \\ *3Institute for Hygiene and Toxicology, Federal Research Centre for Nutrition (BFE) \\ (D-76131 Karlsruhe, Germany) \\ *4Institute for Microbiology, Federal Dairy Research Centre (BafM) \\ (D-24103 Kiel, Germany) \\ *5Federal Institute for Health Protection of Consumers and Veterinary Medicine (BgVV), FB4 \\ (D-07743 Jena, Germany) \\ *6Chemical State Laboratory (Chemisches Untersuchungsamt) \\ (D- 4295 Trier, Germany) \\ ${ }^{*}{ }^{7} \mathrm{I}+\mathrm{G}$ Health Research (D- 80687 Munich, Germany)
}

Key words : ochratoxin A, food contamination, human exposure, German project

(Received, November 15, 2000)

\section{Introduction}

Ochratoxin A (7-L-3-phenylalanylcarbonyl-5-chloro-8-hydroxy-3, 4-dihydro-3-R-methyliso-cumarin) (OTA) is a nephrotoxic and nephrocarcinogenic mycotoxin produced by Penicillium verrucosum in temperate or cold climates and a number of species of Aspergillus in warmer and tropical parts of the world ${ }^{1)}$.

OTA has been found to occur predominantly in cereals and cereal products but also in a variety of other food commodities. By far, most data on the natural occurrence of OTA were obtained from Europe, especially from the Scandinavian countries, Germany and countries of the Balkan area ${ }^{1,2}$. Analyses of human serum samples in several European countries, Canada and Japan (for review of citations see ref. 3) revealed that blood from healthy humans frequently contains ochratoxin $\mathrm{A}$, which indicates a continuous and widespread exposure.

In the recent years the importance of OTA is reflected by the work on risk assessment by different organisations such as the Scientific Committee on Food of the European Commission and the Codex Alimentarius Commission.

To determine the contamination of food with ochratoxin A (OTA) and the exposure of the consumer to this mycotoxin, a study was carried out during 1995 and 1999 by scientists from four research facilities of the Federal Ministry of Nutrition, Agriculture and Forestry (BAGKF, BafM, BFE 
and BAFF in Alliance Product and Nutrition Research) in collaboration with scientists from the Chemical State Laboratory in Trier, the Federal Institute for Health Protection of Consumers and Veterinary Medicine (BgVV), Jena Branch, and I+G Gesundheitsforschung in Munich (Fig. 1). The study was initiated and financed by the German Federal Ministry for Health.

\section{Research Project Ochratoxin A}

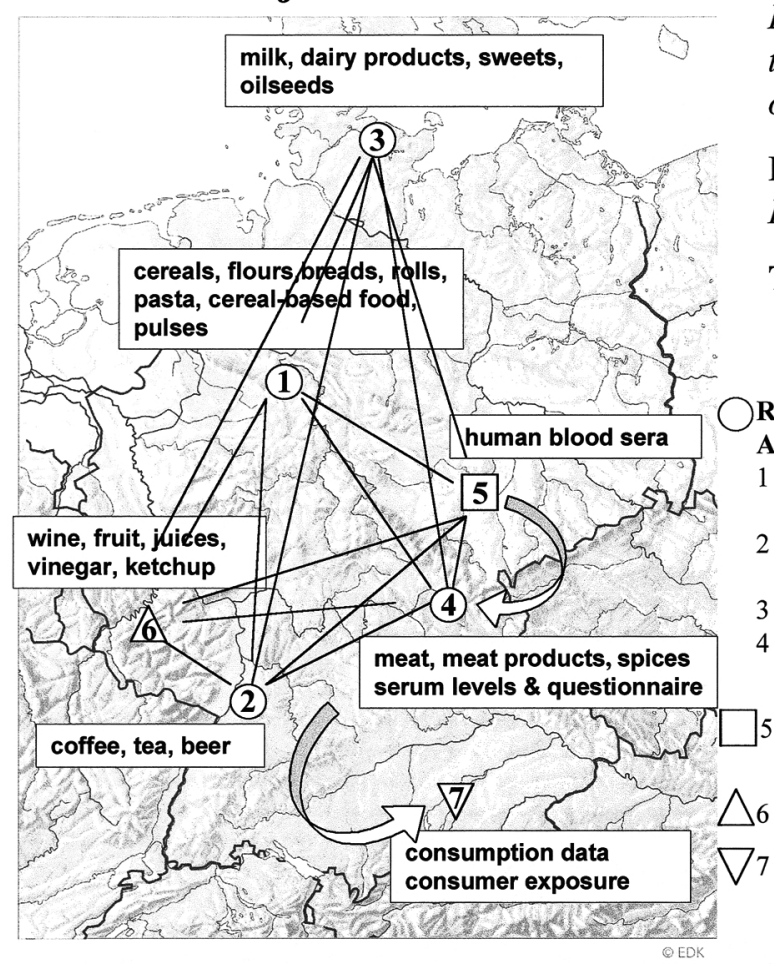

Aim:

Determination of the exposure of consumers to and the contamination of food with ochratoxin $A$

\section{Initiation and support:}

Federal Ministry of Health

Time period: 1995 - 1999

\section{Scientific institutions:}

Research Centers of the Federal Ministry of Nutrition, Agriculture and Forestry

1 Federal Center for Cereal, Potato and Fat Research, BAGKF, Detmold (J.WOLFF )

2 Federal Research Center for Nutrition, BFE, Karlsruhe (H. BRESCH)

3 Federal Dairy Research Center, BAfM, Kiel (G. ENGEL)

4 Federal Center for Meat Research, BAFF, Kulmbach (M. GAREIS, R. SCHEUER, S. EHRHARDT)

5 Federal Inst. For Health Protection of Consumers and Veterinary Medicine, BgVV, Jena (H.ROSNER)

6 Chemical State Laboratory, Trier (P.MAJERUS)

$\checkmark 7$ I+G Health Research, Munich (C.BODECHTEL)

Fig.1 Research Project Ochratoxin A

\section{Study Design and Methodology}

The quantity of OTA ingested by the consumer per day can principally be established in two ways:

- Calculation of the daily intake on the basis of the analytically found OTA concentrations of foods available on the German market and the quantities consumed

- Calculation of the daily intake on the basis of the OTA concentrations found in blood sera of the population and population groups

Provided that the results of both methods used for the establishment of OTA intakes are in agreement, the overall result can be considered as representative of the exposure of the German consumer and the contamination of the foods examined. An agreement can be obtained only if the foods to be examined are selected in such a way that no important nutritional OTA sources are 
missed and that the OTA concentrations of foods are completely ascertained and bioavailable.

The following specific tools which included the fixation of identical criteria for the test persons and the allowance of comparison of the analytical data with the data from the questionnaires have been developed for this study:

- Catalogue of foods to be analysed and to be included in the food intake questionnaires

- Period of and intervals between recording and analysis

- Data bank for analytical and other data

- Food intake questionnaires and calculation factors

- Questionnaires for establishing the test persons' food habits

- Interlaboratory comparison of the food-analyzing laboratories

- Interlaboratory comparison for blood analyses

The catalogue of foods included in the study comprised 29 food groups with 137 sub-groups, e.g. for bread: Wheat bread (mixed meals), rye bread (mixed meals), whole-meal bread, multiple meal bread, toast, crisp bread, various types of rolls etc.

In addition to 25 different beverages (different coffee, beer and wine brands/varieties, juices and cocoa-containing beverages), also milk and milk products, meat and meat products, sweets, pasta, seasonings, oils and oil seeds were examined.

An overview of the study design is given in figure 2, showing that at least 3 data bases (OTA levels in blood, OTA levels in foods, nutrional behaviour) has been created. From these the exposure of the consumer from food items could be determined and calculated and finally the daily intakes compared with the PTDI-values.

\section{Results}

Within this project, almost 7000 food samples and more than 1000 human blood samples were examined for OTA. In parallel, the nutritional and consumption habits of more than 2500 persons were recorded by trained interviewers using questionnaires elaborated by nutritional scientists. With the help of these data, OTA exposure of representative consumer collectives such as vegetarians, infants and adolescents as well as low-level, normal and high-level consumers have been established and compared with OTA concentrations of the blood sera analyzed.

OTA was very frequently detected in blood sera from the German population (98\% positives), although mostly in very low concentrations (median $0.2 \mathrm{ng} / \mathrm{ml}$ ). The toxin was found to be present in $57.2 \%$ of all food samples examined. However, only in $7.3 \%$ of the samples, the concentrations detected were above $0.5 \mu \mathrm{g} / \mathrm{kg}$, in $1.0 \%$, above $3 \mu \mathrm{g} / \mathrm{kg}$ and in $0.5 \%$, above $5 \mu \mathrm{g} / \mathrm{kg}$.

This study shows that apart from cereals and cereal products, coffee and beer also vegetable/fruit juices, wine, sweets/chips, cocoa and raisins may contribute to OTA intakes by the consumer. Also in ketchup and vinegar, OTA has been detected.

OTA is also detectable in some foods of animal origin. This should be attributable to OTAcontaining feeding stuffs. Some pork products such as kidney and liver, as well as liver sausage and black pudding, also contribute to the overall exposure of the consumer. Poultry, beef and milk are practically free of OTA. Milk products may be contaminated only by OTA-containing additives such as 


\section{German Research Project Ochratoxin A}

\section{Contamination of Food with Ochratoxin A and Consumer Exposure}

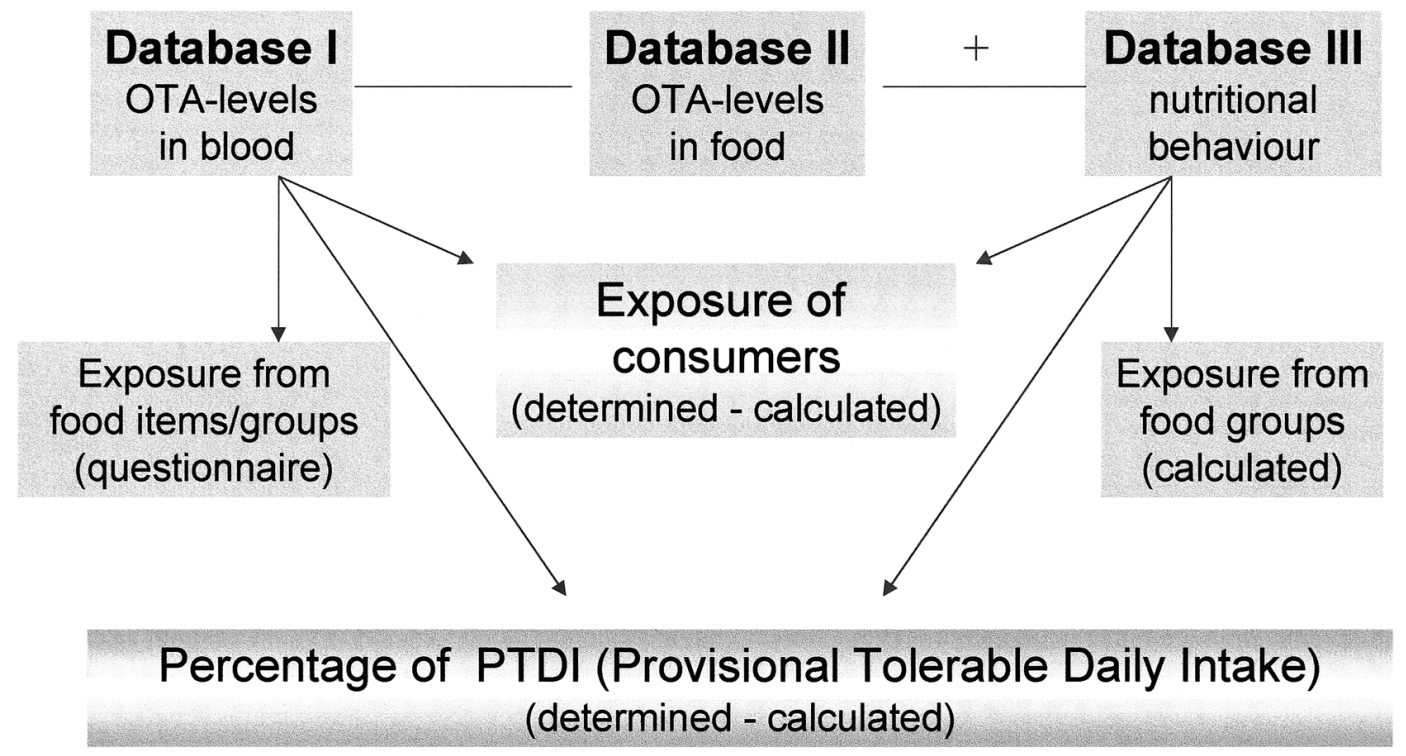

Fig.2 German Research Project Ochratoxin A, Contamination of Food with Ochratoxin A and Consumer Exposure

spices $^{4)}$, muesli or dried fruit.

For adults in Germany, levels in the range of 0.5 to $0.6 \mathrm{ng} / \mathrm{kg}$ body weight were established on the basis of the mean-case variant (50th percentile, mean plausible portion sizes) for all strata values. The level of OTA intake per $\mathrm{kg}$ body weight by consumers with a mostly vegetarian diet did not differ from that of the population. Within this population, no sex- or age-specific differences were found for OTA intake per $\mathrm{kg}$ body weight. However, statistical analyses showed a significant effect due to location in Germany in connection with a higher intake of certain foods. Among the food groups the intake of OTA is mainly due to cereals and cereal products, coffee and beer.

For children, in particular in the younger age groups, the OTA intake per kg body weight was calculated to be distinctly higher than for adults. The mean daily intake by the 574 children examined in the age group of 4 to 13 years was between 0.7 and $1.2 \mathrm{ng} / \mathrm{kg}$ body weight for the mean-case variant. Above all in the age group of 4 to 9 years, OTA intake was more than $1 \mathrm{ng} / \mathrm{kg}$ body weight for the mean-case variant. In literature, no recommendations for children could be found. However, it is to be assumed that more stringent guidelines must be fixed than for adults. Public health measures or recommendations for maximum limits should, above all, take into account the OTA exposure of children.

The provisional tolerable daily intake (PTDI) estimated by the EU Scientific Committee for Food in 1998 should be below $5 \mathrm{ng} / \mathrm{kg}$ bw. The results of the present study show that, in view of the foods 
available on the German market at the present time and the food habits of the German population, the daily OTA intake of the consumer in Germany, established by using two different methods, is 0.5 $\mathrm{ng} / \mathrm{kg}$ body weight. Thus, a percentage of between $9 \%$ and $31 \%$ of the PTDI levels is covered.

At present, maximum tolerable levels for OTA in cereals $(5 \mu \mathrm{g} / \mathrm{kg})$ and cereal products $(3 \mu \mathrm{g} / \mathrm{kg})$ are recommended and under discussion in the European Union.

The complete results and data of the OTA-project are published in the journal Archiv fur Lebensmittelhygiene $\left(\right.$ Vol. 50) ${ }^{5-12)}$.

\section{References}

1) Pittet, A. Rev. Med. Vet., 149, 479-492 (1998)

2) Kuiper-Goodman, T. and Scott, P.M.: Biomed. Environ. Sci., 2, 179-248 (1989)

3 ) Scott, P.M., Kanhere, S.R., Lau, B.P.Y., Lewis, D.A., Haywarf, S., Ryan, J.J. and Kuiper-Goodman, T.: Food Addit. Contam., 15, 555-562 (1998)

4 ) Vrabcheva, T., Gareis, M., Bresch, H., Bodechtel, C., Engel, G., Majerus, P., Rosner, H., Wolff, J.: Rev. Med. Vet., 198, 533 (1998)

5 ) Bresch, H., Urbanek, M. and Hell, K: Arch. Lebensmittelhyg, 51, 89-94 (2000)

6 ) Cholmakov-Bodechel, C., Schneider, R., Wolff, J., Gareis, M., Bresch, H., Engel, G., Majerus, P. AND Rosner, H: Ochratoxin A: Arch. Lebensmittelhyg, 51, 111-115 (2000)

7 ) Enger, G.: Arch. Lebensmittelhyg, 51, 98-101, (2000)

8 ) Gareis, M. and Scheuder, R.: Arch. Lebensmittelhyg, 51, 102-104 (2000)

9 ) Gareis, M., Rosner, H. and Ehrhardt, S.: Arch. Lebensmittelhyg, 51, 108-110 (2000)

10) Majerus, P., Brescf, H. and Otteneder, H.: Arch. Lebensmittelhyg, 51, $95-97$ (2000)

11) Rosner, H., Rohrmann, B. and Peiker, G. : Arch. Lebensmittelhyg, 51, 4-5, $104-107$ (2000)

12) Wolff, J. : Arch. Lebensmittelhyg, 51, 85-88 (2000) 